\title{
Fungal Vaccines and Immunotherapeutics
}

\author{
Evelyn Santos and Stuart M. Levitz \\ Department of Medicine, University of Massachusetts Medical School, Worcester, Massachusetts 01655 \\ Correspondence: stuart.levitz@umassmed.edu
}

Concomitant with the increased prevalence of immunocompromised persons, invasive fungal infections have become considerably more frequent in the last 50 years. High mortality rates caused by invasive mycoses and high morbidity because of intractable mucosal infections have created an unmet need for innovative prophylactic and therapeutic strategies against fungal pathogens. Several immunotherapeutics and vaccines are in development to address this need, although one has yet to reach the clinic. This review focuses on past and current immunotherapeutic and vaccine strategies being tested to either prevent or treat fungal infections, as well as the challenges associated with their development.

\section{THE CASE FOR IMMUNOTHERAPY AND VACCINE DEVELOPMENT AGAINST FUNGI}

$T_{\text {he }}^{\text {h }}$ he burden of fungal pathogens to human health has substantially increased in the past half century attributable, in large part, to the burgeoning numbers of immunocompromised individuals. For example, in the early 1980s, the endemic fungus, Histoplasma capsulatum, caused the majority of invasive mycosis in the United States, with an estimated incidence rate of 13.9 cases per million per year. By 2003, opportunistic fungal infections rose to prominence causing more than 300 cases of invasive mycosis per million per year in the United States (Pfaller and Diekema 2010). This staggering increase was partly because of the emergence of AIDS, which predisposes hosts to opportunistic pathogens such as Cryptococcus neoformans, the most common invasive fungal pathogen in this population. In fact, the incidence rate of cryptococcosis peaked in the early 1990s in the
United States before highly active antiretroviral therapy (HAART) became widely available by the end of the decade. The effect of HAART on the decrease in incidence of cryptococcosis is evident in cities such as Houston, TX, which saw a $92 \%$ decline in cases of cryptococcosis in its HIV-infected population from 1993 to 2000 (Pfaller and Diekema 2010). However, in subSaharan Africa, where HAART is not as widely accessible, cryptococcal meningitis may surpass tuberculosis in mortality, killing an estimated 530,000 people yearly (Park et al. 2009).

In most of the developed world, immunosuppression caused by AIDS accounts for only a minority of invasive fungal infection (IFI) cases. Only $4 \%$ of all patients diagnosed with invasive mycoses in the United States have HIV (Pfaller and Diekema 2010). The vast majority of IFIs are contracted in a hospital setting, where Candida species (spp.) rank fourth among causes of nosocomial bloodstream infections. In fact, $\sim 80 \%$ of candidemia cases occur in the absence

Editors: Arturo Casadevall, Aaron P. Mitchell, Judith Berman, Kyung J. Kwon-Chung, John R. Perfect, and Joseph Heitman

Additional Perspectives on Human Fungal Pathogens available at www.perspectivesinmedicine.org

Copyright (C) 2014 Cold Spring Harbor Laboratory Press; all rights reserved; doi: 10.1101/cshperspect.a019711

Cite this article as Cold Spring Harb Perspect Med 2014;4:a019711 
of overt immunosuppression. In these patients, risk factors associated with infection are largely related to medical interventions, such as the use of broad-spectrum antibiotics or placement of a central venous catheter. The remaining $20 \%$ of cases occur in classically immunosuppressed patients who are at greatest risk for developing IFIs over their lifetime. These patients often suffer from hematologic malignancies, undergo cancer chemotherapy or other immunosuppressive therapy, or are recipients of organ or bone marrow transplants (Perlroth et al. 2007).

Although medical intervention contributes to the high IFI incidence, fungal infections are generally underdiagnosed. This is, in part, a result of nonspecific clinical signs and symptoms associated with these infections, as well as the lack of sensitive diagnostic tests for some of the mycoses (Brown et al. 2012). Such obstacles can hinder the timely administration of antifungals, substantially contributing to high mortality rates (Perlroth et al. 2007; Pfaller and Diekema 2010).

Even if an accurate diagnosis is achieved early in infection or empiric treatment started for symptomatic patients presenting with relevant risk factors, overall mortality rates for both endemic and opportunistic IFIs are still quite high (Pfaller and Diekema 2010). Mortality rates attributable to invasive candidiasis can reach $40 \%$ despite empiric treatment (Perlroth et al. 2007). Several factors contribute to such high case fatality rates. First, most patients presenting with IFIs have serious underlying diseases (Pfaller and Diekema 2010; Dimopoulos et al. 2013). Second, several of the antifungals currently available can cause severe side effects and adversely interact with many of the other drugs routinely administered (Dimopoulos et al. 2013). Last, susceptibility to these antifungals is highly variable across fungal species, and emerging resistance is an increasing concern (Pfaller and Diekema 2010; Brown et al. 2012).

Although invasive mycoses are the most deadly manifestation of fungal infections, cutaneous mycoses are much more common (Brown et al. 2012). In particular, mucosal candidiasis affecting the oral cavity and gastrointestinal and genitourinary tracts can significantly im- pact quality of life and are often refractory to antifungals (Vecchiarelli et al. 2012). Recurrent vulvovaginal candidiasis, for example, affects $\sim 75$ million women of childbearing age worldwide (Brown et al. 2012), and long-term use of antifungal agents in this population is thought to be contributing to the emergence of resistant strains (Vecchiarelli et al. 2012). Thus, there is a significant need for new therapies targeting both invasive and mucosal mycoses.

Currently, there are no immunotherapeutics or vaccines approved for the treatment or prevention of fungal infections. Several candidates are in the preclinical stage of development and two vaccines against Candida spp. are undergoing clinical trials (De Bernardis et al. 2012; Schmidt et al. 2012). Reviewed here are therapeutic and prophylactic strategies that rely on the immune system or specific immune components (Table 1). Important concepts and challenges involved in the eradication and resolution of fungal infections are exemplified.

\section{IMMUNOTHERAPY}

Generally, fungal immunotherapy involves the administration of exogenous immune agents, such as white cells, antibodies, and cytokines, to beneficially alter the course of infection (Dan and Levitz 2006; Armstrong-James and Harrison 2012). Reviewed below are monoclonal antibodies (mAbs) and dendritic cell (DC) therapy, and vaccine strategies developed to treat or prevent fungal infections.

\section{Antibody Therapy}

Antibodies or immunoglobulins recognize diverse antigens through the genetic rearrangement and somatic hypermutation of its variable regions (Schroeder and Cavacini 2010). Constant regions, designated by an immunoglobulins isotype, are recognized by Fc receptors $(\mathrm{FcR})$ on immune cells and $\mathrm{Clq}$, a factor involved in the complement cascade that can lead to bacterial but not fungal lysis. Fungi resist lysis by porting a rigid cell wall composed of a skeletal framework of fibrillar polysaccharides cemented by amorphous polysaccharides dec- 
Fungal Vaccines and Immunotherapeutics

Table 1. Therapeutic and prophylactic strategies that rely on the immune system or specific immune components

\begin{tabular}{|c|c|c|c|}
\hline Strategy & Potential pros & Potential cons & Design considerations \\
\hline $\begin{array}{l}\text { Passive antibody } \\
\text { therapy }\end{array}$ & $\begin{array}{l}\text { Adjuvant to current antifungals } \\
\text { Direct antifungal/fungistatic activity }\end{array}$ & $\begin{array}{l}\text { Emergence of fungal } \\
\text { resistance }\end{array}$ & $\begin{array}{l}\text { Target accessible to the } \\
\text { antibody } \\
\text { Antibody isotype and } \\
\text { IgG subclass }\end{array}$ \\
\hline $\begin{array}{l}\text { DC immunotherapy/ } \\
\text { vaccine }\end{array}$ & $\begin{array}{l}\text { Adjuvants that are too toxic to } \\
\text { administer to humans can be } \\
\text { directly delivered DCs ex vivo }\end{array}$ & $\begin{array}{l}\text { DC vaccination may } \\
\text { not be feasible in } \\
\text { most populations } \\
\text { Costly }\end{array}$ & DC subtype selection \\
\hline $\begin{array}{l}\text { Attenuated/killed } \\
\text { vaccine }\end{array}$ & $\begin{array}{l}\text { Provides numerous antigens specific } \\
\text { for the pathogen } \\
\text { Protection can be induced } \\
\text { independent of } \mathrm{CD} 4^{+} \mathrm{T} \text { cells }\end{array}$ & $\begin{array}{l}\text { Risk of inducing an } \\
\text { infection or } \\
\text { dysregulated } \\
\text { inflammatory } \\
\text { response }\end{array}$ & $\begin{array}{l}\text { Attenuation must be } \\
\text { irreversible }\end{array}$ \\
\hline $\begin{array}{l}\text { Recombinant protein } \\
\text { (subunit) vaccine }\end{array}$ & $\begin{array}{l}\text { Specifically formulated to elicit a } \\
\text { protective response } \\
\text { Safer than attenuated vaccines, } \\
\text { especially in immunosuppressed }\end{array}$ & $\begin{array}{l}\text { T-cell responses to } \\
\text { antigens may differ } \\
\text { as a function of } \\
\text { HLA haplotype }\end{array}$ & $\begin{array}{l}\text { Antigen must be present } \\
\text { on all strains of the } \\
\text { fungus }\end{array}$ \\
\hline Conjugate vaccines & $\begin{array}{l}\text { Can be formulated to induce } \\
\text { responses against glycan and/or } \\
\text { protein antigens } \\
\text { Can be self-adjuvanting } \\
\text { Safer than attenuated vaccines in } \\
\text { immunosuppressed }\end{array}$ & $\begin{array}{l}\text { T-cell responses to } \\
\text { antigens may differ } \\
\text { as a function of } \\
\text { HLA haplotype }\end{array}$ & $\begin{array}{l}\text { Antigen(s) must be } \\
\text { present on all strains } \\
\text { of the fungus }\end{array}$ \\
\hline
\end{tabular}

IgG, immunoglobulin G; DC, dendritic cell; HLA, human leukocyte antigen.

orated with surface proteins. The innermost layer of the fibrillar framework is composed of chitin cross linked to $\beta$-1,3-glucans that expand outward. These two polysaccharides are common among fungi, making them attractive therapeutic targets. The chemical identity of the amorphous polysaccharides differs among species, although it generally includes mannans of varying lengths and linkages (Latge 2010). Although fungi evade lysis by the complement system, deposition of complement components, such as C3b and iC3b on its surface, leads to its opsonization, enabling phagocyte recognition of fungal particles (Cutler et al. 2007).

In many instances, ingestion of pathogens opsonized by antibody and/or complement leads to killing and protection to the host; however, in some cases, antibodies are not protective. For example, H1C, an IgG1 mAb specific for an uncharacterized $70-\mathrm{kDa}$ protein on the surface of $H$. capsulatum, showed no protective effect when given $2 \mathrm{~h}$ before challenge, despite enhancing phagocytosis by a murine macrophage cell line (J774.16) (Lopes et al. 2010). In contrast, the same group treated mice in a similar fashion with IgG1 mAbs against heat shock protein 60 , and these mice were protected from infection (Guimaraes et al. 2009). This discrepancy illustrates how the identity of the antigen targeted by an antibody is an important factor in determining its effectiveness.

Furthermore, the epitope recognized by an antibody can also play a role in its effectiveness during an infection. This was illustrated by Casadevall and coworkers, who characterized monoclonal IgMs produced by two hybridoma cell lines derived from the same B cell (Mukherjee et al. 1995; Nussbaum et al. 1997). Because of somatic mutations, the mAbs differed by 11 residues in their variable regions and, therefore, recognized different epitopes on the capsule produced by C. neoformans. Although they showed similar half-lives and were able to agglutinate fungal particles, one monoclonal IgM 
(13F1) penetrated the capsule, recognizing an epitope found throughout the length of the capsule (Fig. 1). The other monoclonal IgM (12A1) bound epitopes found mostly on the outer surface of the capsule and, when given before infection, this $\mathrm{mAb}$ was found to be more protective than 13F1 (Mukherjee et al. 1995; Nussbaum et al. 1997).

The constant region of an antibody also contributes to its effectiveness. This region is determined by a B cell's activation status and the signals it receives from $\mathrm{CD} 4^{+} \mathrm{T}$ cells. After binding an antigen recognized by a surfacebound IgD or monomeric IgM, B cells become activated and start producing pentameric IgM (Cutler et al. 2007). As CD4 ${ }^{+} \mathrm{T}$ cells also become activated, they start producing cytokines, such as interleukin-4 (IL-4) or interferon- $\gamma$ (IFN- $\gamma$ ), and up-regulate the expression of CD40 ligand on their surface. These molecules engage their respective receptors on the surface of B cells and induce the rearrangement of the constant region in the immunoglobulin produced (Kehry and Hodgkin 1993; Kehry and Castle 1994). This rearrangement is known as "isotype switching" and, depending on the cytokine signal, B cells will produce IgE, IgA, or a subclass of IgG instead of IgM. For example, in humans, IL-4 will induce IgG4 or IgE production, whereas IFN- $\gamma$ induces IgG1. The IgG subclass and isotype induced by each cytokine differ between humans and mice. Therefore, in mice, IL-4 will induce IgG1 and IgE production, whereas IFN- $\gamma$ induces mainly IgG2a (Mestas and Hughes 2004; Murphy et al. 2012b).

A number of studies have looked at the impact of the constant region on the effectiveness of mAbs. For example, when a human hybridoma cell line (3E5) spontaneously switched from producing a nonprotective anticapsular IgG3 antibody against $C$. neoformans to producing an IgG1 antibody with the same variant regions, the IgG1 isotype was found to prolong survival in mice after infection (Yuan et al. 1995). Another group used the same hybridoma cell line to test the efficacy of additional human IgG subclasses. Beenhouwer et al. (2007) constructed recombinant human IgG1, IgG2, IgG3, and IgG4 mAbs by cloning the variable region expressed by $3 \mathrm{E} 5$ cells into expression vectors containing the sequence for each IgG subclass. After challenge with C. neoformans, IgG2 and IgG4 were shown to provide better protection than IgG1 or IgG3.

The elements that recognize the constant regions of antibodies, namely, FcRs and C1q,
A

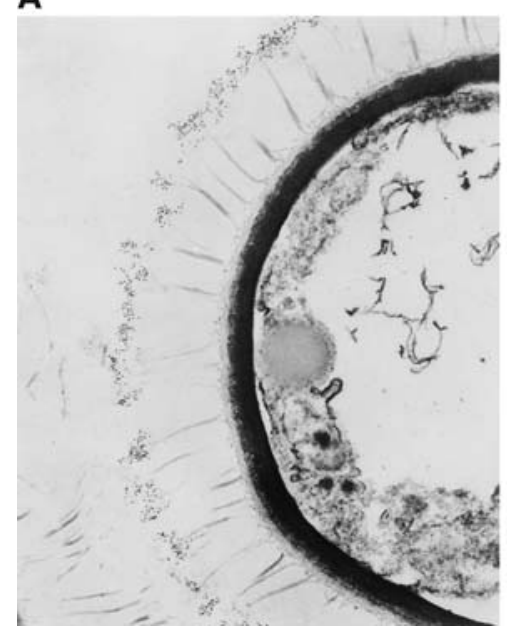

B

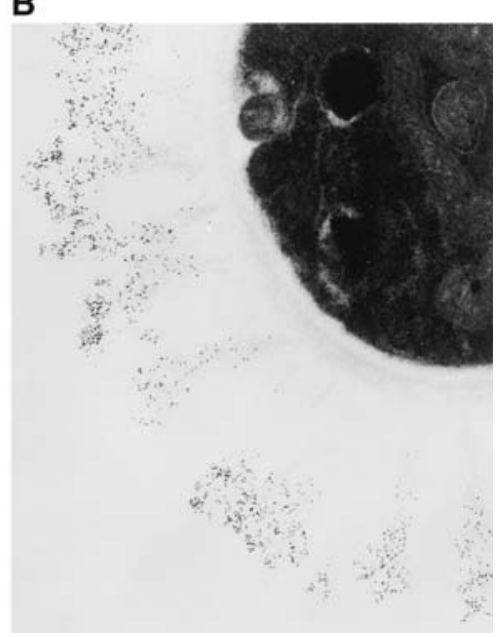

Figure 1. Epitope recognition pattern. (A) Anticapsular monoclonal IgMs 12A1, and (B) 13F1 on C. neoformans yeasts as shown by immunoelectron microscopy. (From Nussbaum 1997; reprinted, with permission, from The Rockefeller University Press (C) 1997.) 
Fungal Vaccines and Immunotherapeutics

are likely responsible for the discrepancy in the protection afforded by the different IgG subclasses. C1q and the seven human and five murine FcRs have varying affinities for each IgG subclass (Schroeder and Cavacini 2010; Bruhns 2012). Additionally, FcRs and the eight complement receptors that mediate phagocytosis are expressed by different immune cell types and regulate a diverse array of cell functions, including degranulation and proliferation (Ricklin et al. 2010; Bruhns 2012). This complexity allows for the flexibility needed to respond to the wide variety of insults handled by the immune system.

Some mAbs possess antifungal properties that are independent of immune cell activity. For example, when incubated with $C$. neoformans, 2G8(IgG2b) prevents capsule formation and reduces capsule size (Hole and Wormley 2012). 2G8 has also been found to be fungistatic against Candida albicans and prevent its attachment to human epithelial cells in vitro (Phan et al. 2007; Torosantucci et al. 2009; Dwivedi et al.2011). The efficacy of $2 \mathrm{G} 8$ in vivo has shown therapeutic promise in mouse models of pulmonary cryptococcosis, as well as invasive and vaginal candidiasis (Torosantucci et al. 2009; Capodicasa et al. 2011; Hole and Wormley 2012).

Another antibody-mediated intervention being tested for the treatment of fungal infections involves labeling an anticapsular IgG1 $\mathrm{mAb}$ (18B7) specific for C. neoformans with radioactive isotopes. The isotopes, ${ }^{213}$ bismuth and ${ }^{188}$ rhenium, which emit $\alpha$ and $\beta$ particles, respectively, have been shown to significantly prolong survival of infected mice (Dadachova et al. 2003). Additionally, ${ }^{213} \mathrm{Bi}-18 \mathrm{~B} 7$ was shown to be superior to amphotericin in clearing disseminated C. neoformans (Bryan et al. 2010). An advantage of therapeutics, such as the fungistatic 2G8 antibody and radiolabeled antibodies, is that their effectiveness is independent of a host's immunological status, making them excellent contenders in treating IFIs in immunocompromised patients. A drawback specific to passive anticapsular antibody therapy, however, is that Cryptococcus spp. shed their capsule during infection. This phenomenon could lead to antibody forming immune complexes with circu- lating capsule rather than promoting opsonophagocytosis or direct antifungal activity in target tissues (Hogan et al. 1996).

Other disadvantages, which could be potentially associated with passive antibody therapy, include (but are not limited to) the emergence of resistance, inconsistent protection across patient populations, and dependence on early diagnosis for optimal protection. The emergence of resistance to mAbs would most likely occur for therapies that target fungal proteins, which can lose or mask the antibody-binding site while maintaining function. Additionally, antibodies that require recognition by host factors to be protective may be ineffective in patient populations in which these factors fail to optimally function with that specific antibody isotype. These variations may be a result of single nucleotide polymorphisms or severe immunodeficiencies that may be contingent on that patient's risk factors in contracting the infection. For example, if the mechanism by which a specific antibody delivers protection requires a healthy neutrophil population, then neutropenic patients would not be expected to benefit from such treatment. Finally, antibody therapy may be most effective when the organism burden is low early in infection, which would require better diagnostic tools than are available today. However, the study of how mAbs specific for fungi affects disease outcome not only contributes to the development of potential therapies but could also assist in the development of better diagnostic tools and help provide clues on how to design a protective vaccine.

\section{Dendritic Cell Immunotherapy and Vaccination}

DC immunotherapy involves incubating or "pulsing" DCs ex vivo with select antigens or pathogens, then returning the cells to the host to boost protection against an infectious agent. This therapeutic strategy can be contrasted to DC vaccination, in which the goal is to protect the host against future pathogen exposure. Although the technical process is the same, the major difference between the two strategies comes down to the timing of the intervention. 
DC vaccination requires that the treatment be performed before infection and DC immunotherapy happens after diagnosis.

DCs are activated after sensing pathogenassociated molecular patterns through pattern recognition receptors (PRRs), which induce the up-regulation of cytokines and costimulatory proteins (Toews 2001; Cassone 2008). These proteins engage their receptors on the surface of $\mathrm{T}$ cells that recognize antigens presented by DCs on major histocompatibility complex (MHC) molecules (Toews 2001). Depending on the cytokines produced, $\mathrm{CD} 4^{+} \mathrm{T}$ cells will differentiate into a specific $\mathrm{T}$ helper $\left(\mathrm{T}_{\mathrm{H}}\right)$ subtype (Murphy et al. 2012a). For example, if DCs produce IL-12, CD ${ }^{+} \mathrm{T}$ cells will emerge as $\mathrm{T}_{\mathrm{H}} 1$ cells. Each $\mathrm{T}_{\mathrm{H}}$ subtype will produce a set of cytokines that will induce a particular set of immune responses. The $\mathrm{T}_{\mathrm{H}}$ subtypes that correlate best with protection against fungi are $\mathrm{T}_{\mathrm{H}} 1$ and $\mathrm{T}_{\mathrm{H}} 17$ (Hamad 2008; Carvalho et al. 2012; Iannitti et al. 2012). $\mathrm{T}_{\mathrm{H}} 1$ cells produce IFN- $\gamma$, which induces cell-mediated immunity by activating phagocytes. $\mathrm{T}_{\mathrm{H}} 17$ cells produce IL-17 and IL-22, augmenting a neutrophilic response and stimulating the production of antimicrobial peptides in the affected tissue. Finally, Treg cells produce transforming growth factor- $\beta$ and IL-10 and help contain the inflammatory process instigated by the other cell types (Iannitti et al. 2012).

One peptide that has shown promise as an antigen for DC immunotherapy is P10, a 15amino acid synthetic oligomer that has been previously mapped to be a T-cell epitope found on a highly immunogenic protein secreted by Paracoccidioides brasiliensis (Taborda et al. 1998). When bone marrow DCs pulsed with P10 were given subcutaneously to naïve mice that were subsequently infected with $P$. brasiliensis yeasts, researchers found an $\sim 2$-log decrease in fungal burden in immunized mice compared with control groups. This strategy was also successful in decreasing fungal burdens in the lungs of mice infected 30 days before therapy, suggesting that this strategy can be therapeutic as well as prophylactic (Magalhaes et al. 2012).

Although DCs act mainly as antigen-presenting cells (APCs), they are a heterogeneous population of cells that express different combinations of PRRs. Depending on the stimulus sensed, distinctive DC subsets will induce disparate T-cell responses. Therefore, the subset of a specific DC population must be taken into account when designing DC immunotherapy strategies. Romani and coworkers (2006) used two distinctive DC populations in a strategy that modeled bone marrow transplantation in mice. In this study, C57BL/6 mice transplanted with lymphocyte-depleted bone marrow from BALB/ $\mathrm{c}$ mice were immunized with conventional dendritic cells (cDCs) or plasmacytoid dendritic cells (pDCs) pulsed with Aspergillus fumigatus conidia. Mice then received a pulmonary challenge with $A$. fumigatus 14 days after transplant. The group that received pDCs was $100 \%$ protected, whereas mice that received cDCs generally died within 10 days after challenge. pDCimmunized mice had higher levels of Treg cells in draining lymph nodes after infection, whereas $\mathrm{cDC}$-immunized mice had higher levels of IFN- $\gamma$, indicative of a strong $\mathrm{T}_{\mathrm{H}} 1$ response (Romani et al. 2006). The outcome in this experiment illustrates how an overzealous inflammatory response induced by vaccination may result in undesirable consequences for the host.

DC vaccination may not be economically tenable for prophylaxis of the general population; however, it could be feasible in high-risk groups such as bone marrow transplant patients. DC immunotherapy may prove useful as an adjunctive therapy in established fungal infections. Additionally, understanding how DCs provide protection against specific pathogens helps narrow down antigen components formulated in potential vaccines (Steinman and Banchereau 2007). Other fungal vaccination strategies target specific receptors on DCs, particularly Dectin-1, a PRR that binds $\beta$-glucans. Dectin-1 has been shown to be indispensable for host defenses against several fungal pathogens by linking fungal cell wall recognition to $\mathrm{T}_{\mathrm{H}} 1$ and $\mathrm{T}_{\mathrm{H}} 17$ responses (Hardison and Brown 2012). Antigen-loaded glucan particles derived from Saccharomyces cerevisiae cell walls deliver their cargo to DCs resulting in antigen-specific antibodies and $\mathrm{T}_{\mathrm{H}} 1 / \mathrm{T}_{\mathrm{H}} 17$-biased $\mathrm{CD} 4{ }^{+} \mathrm{T}$-cell response (Huang et al. 2012, 2013). 
Fungal Vaccines and Immunotherapeutics

\section{VACCINES}

As a prophylactic strategy, vaccination has had unparalleled success in preventing morbidity and mortality from infectious diseases (Roush and Murphy 2007). However, currently there are no fungal vaccines approved for human use. This is partly because of the stringent safety and effectiveness criteria vaccines must meet to be licensed. Because the intended population for preventive vaccines is generally healthy, benefit to risk ratios for a new vaccine must be very high. Therefore, vaccines have to be safe, inflict few side effects, and sustain long-term protection in a population with varied genetic backgrounds and MHC haplotypes (Levine and Sztein 2004). A less favorable side effect profile may be tolerated for therapeutic vaccines that provide benefits over existing treatments.

Despite these hurdles, there are two antiCandida recombinant protein vaccines that are currently in clinical trials. Additionally, there are several other fungal vaccines in preclinical development. These include killed and live-attenuated whole cell vaccines, as well as subunit recombinant protein and polysaccharide-protein conjugate vaccines. Each of these strategies has unique advantages and disadvantages, which will be discussed below but most target antigens that are specific for only one fungal genus. At least two strategies, however, take advantage of the common epitopes found in the skeletal framework of the fungal cell wall. One uses killed S. cerevisiae to direct immune cells to recognize common fungal wall polysaccharides including glucans and mannans (Liu et al. 2011a). Another universal vaccine design uses $\beta$-glucans conjugated to an inactivated version of diphtheria toxin to elicit responses against different pathogenic fungi (Torosantucci et al. 2005). These aforementioned studies are described at greater detail below.

\section{Killed and Attenuated Vaccines}

The first vaccines used to immunize humans were developed empirically by exposing indi- viduals to attenuated or killed pathogens to elicit immunological memory. Several studies have evaluated the effectiveness of killed and attenuated fungi as potential vaccines, including $S$. cerevisiae, which has the potential to protect individuals from the major fungal pathogens. Immunization with heat-killed $S$. cerevisiae yeasts (HKY) by subcutaneous injection has been shown to be protective against $C$. albicans (Liu et al. 2012a), A. fumigatus (Liu et al. 2011a), and the endemic fungus Coccidioides posadasii (Capilla et al. 2009). Presumably, immunization with $S$. cerevisiae offers protection against a variety of fungi because it shares with them common polysaccharide epitopes found on its cell wall. Additionally, it may also elicit responses that are cross-reactive to homologous proteins found on pathogenic fungi (Liu et al. 2011a). Although protective against many different fungi, HKY is less effective in preventing mortality in models of coccidioidomycosis than a more specific vaccination regimen using formalin-killed Coccidioides immitis spherules (FKS). Vaccination with HKY or FKS protected $70 \%$ and $100 \%$ of CD1 mice, respectively, from an otherwise lethal $C$. immitis challenge (Capilla et al. 2009). Inasmuch as S. cerevisiae acts as a universal fungal vaccine, it may lack sufficient specificity to be as effective as vaccines that contain pathogenic fungal antigens. Whether these studies could be translated to humans, who have greater natural exposure to fungi than laboratory mice living in filtered cages, is unclear. Notably, a phase III placebocontrolled clinical trial evaluating the efficacy of the FKS vaccine found it to be ineffective in preventing coccidioidomycosis or mitigating severity of disease (Pappagianis 1993).

Xue et al. (2009) developed another whole fungal cell vaccination strategy against coccidioidomycosis. This group vaccinated $\mathrm{BALB} / \mathrm{c}$ and C57BL/6 mice with an attenuated strain of C. posadasii, which cannot endosporulate because of the loss of two chitinase genes. They found that two subcutaneous injections with the attenuated strain 14 days apart protected $75 \%-100 \%$ of the animals from an otherwise lethal pulmonary challenge with the virulent C735 strain of C. posadasii (Xue et al. 2009). 
Attenuated live vaccines generally have a good safety profile in immunocompetent individuals; however, they may still cause an infection or a dysregulated inflammatory response in immunosuppressed individuals (Pirofski and Casadevall 1998). Therefore, this strategy may be most appropriate in the case of endemic fungi, which can infect immunocompetent individuals (Chu et al. 2006). However, there are exceptions to this rule depending on the type of immunosuppression, as the Centers for Disease Control and Prevention recommend that certain live vaccines be administered to a subset of immunocompromised patients (ACIP 2011). An attenuated version of Blastomyces dermatitidis, also an endemic fungus, has been tested as a possible immunization strategy in settings of low CD4 $4^{+}$T-cell counts as encountered in AIDS patients. Deletion of Blastomyces adhesin-1 (BAD1) in this dimorphic fungus renders the organism avirulent in mouse models of disease. Subcutaneous immunization with this mutant $(\triangle \mathrm{BAD} 1)$ protected $100 \%$ of $\mathrm{CD} 4^{-/-}$mice from a lethal inoculum (Wuthrich et al. 2003).

Yet, another live vaccine strategy that has been successful in a $\mathrm{CD}^{+}$T-cell-deficient mouse model involved immunizing mice with a C. neoformans strain engineered to produce murine IFN- $\gamma(\mathrm{H} 99 \gamma)$. This strain has been previously shown to protect mice from infection with the wild-type $C$. neoformans strain by inducing a $\mathrm{T}_{\mathrm{H}} 1$ response (Wormley et al. 2007). In a more recent study, depletion of $\mathrm{CD} 4^{+}$or $\mathrm{CD} 8^{+}$ T cells during the immunization phase ( primary infection with $\mathrm{H} 99 \gamma$ ) or secondary lethal infection protected $100 \%$ of mice from mortality. However, when both $\mathrm{CD} 4^{+}$and $\mathrm{CD} 8^{+} \mathrm{T}$ cells were depleted during immunization with $\mathrm{H} 99 \gamma$ or secondary infection, mortality reached 100\% (Wozniak et al. 2011). Although the H99 $\gamma$ strain vaccine could not be used in humans, it does serve as a proof of concept for live vaccination strategies, whereby pathogens are genetically engineered to produce cytokines that enhance host-protective responses.

Killed and attenuated vaccines are highly effective in combating opportunistic and endemic fungal infections. It is possible that the $\triangle \mathrm{BAD} 1$ attenuated $B$. dermatitidis vaccine and a humanized version of $C$. neoformans $\mathrm{H} 99 \gamma$ vaccine could protect individuals with low $\mathrm{CD} 4^{+}$ T-cell counts, such as HIV patients. However, assuring the safety of attenuated vaccines in the immunosuppressed population has historically been challenging, as previously discussed. In immunocompetent individuals, attenuated vaccines against viral infections have been highly successful, and perhaps an attenuated vaccine against an endemic fungal pathogen may contribute to the eradication of these diseases where they are prevalent.

\section{Recombinant Protein Vaccines}

The increased knowledge obtained in the last century in the fields of microbial pathogenesis and basic immunology has contributed to the development of acellular vaccines. In particular, recombinant protein vaccines would not be possible without our increased understanding of the innate immune system, especially the role DCs play in shaping the adaptive immune response. With some exceptions, protein antigens by themselves are not sufficient to activate APCs and elicit an adaptive immune response. Therefore, acellular vaccines are frequently formulated with an adjuvant to potentiate the immunogenicity of the antigen and skew adaptive immunity to the appropriate response. Many adjuvants are microbial products that activate APCs by binding PRRs. However, some are still in preclinical evaluation and others are not approved for use in humans because of high toxicity (Tritto et al. 2009; Levitz and Golenbock 2012).

One class of adjuvants that is approved for human use is aluminum salts such as aluminum hydroxide and aluminum phosphate. Commonly known as "alum," this adjuvant elicits strong antibody-mediated responses to admixed antigens (Levitz and Golenbock 2012). As such, alum is commonly used in vaccines that are designed to promote complement-mediated lysis and opsonophagocytosis, as well as neutralize protein toxins, viral particles, and other pathogens from attaching to host tissue (Tritto et al. 2009). NDV-3 (NovaDigm, Grand Forks, ND), an anti-Candida vaccine that in- 
Fungal Vaccines and Immunotherapeutics

cludes the invasin protein agglutinin-like sequence 3 (Als $3 p$ ) and alum in its formulation (Schmidt et al. 2012), prevents yeast attachment and invasion of epithelial and endothelial cells. This strategy works by eliciting IgG and IgA against Als3p (Phan et al. 2007). In a phase I clinical trial, NDV-3 was found to be safe and tolerable in research subjects, and shown to elicit IFN- $\gamma$ - and IL-17A-producing antigen-specific $T$ cells (Schmidt et al. 2012). In animal models, this vaccine protected mice from oropharyngeal, vaginal, and invasive candidiasis (Spellberg et al. 2006; Ibrahim et al. 2013). Furthermore, because of high structural homology between Als3p and clumping factor A on the surface of Staphylococcus aureus, NDV-3 has also been shown to be protective against this highly virulent bacterial pathogen in animal models (Spellberg et al. 2008). If found efficacious in humans, NDV-3 could have a high impact in driving down mortality from hospitalacquired infections by targeting two of the most deadly nosocomial bloodstream infectious agents (Pfaller and Diekema 2010).

Adjuvanticity can also be achieved by attaching a relevant antigen to the shell of a virus. Not only can the shell, or virosome, activate APCs but it also acts as a carrier, delivering a desired antigen to targeted cells. Pevion Biotech (Bern, Switzerland) is developing a virosome-based vaccine against recurrent vaginal candidiasis, targeting secreted aspartyl proteinase-2 (Sap2). Sap2 is a virulence factor that is highly expressed by Candida spp. isolated from vaginal mucosa. This protease hydrolyzes both structural and immune-associated proteins such as complement factors and immunoglobulins (Cassone et al. 2007). Rats immunized with recombinant amino-terminal region of Sap-2 attached to $\mathrm{H} 1 \mathrm{~N} 1$ virosomes showed accelerated clearance of vaginal candidiasis, and were shown to produce IgA and IgG against Sap2 in vaginal fluid (De Bernardis et al. 2012). Although results have not yet been published, a phase I clinical trial has been conducted (NIH 2010).

In contrast to whole cell vaccines, recombinant vaccines are generally much safer, particularly for use in immunocompromised patients (ACIP 2011). However, designing recombinant vaccines can be quite challenging because antigens have to be chosen on the basis of immunogenicity and potential effectiveness to conserve human and economic resources needed to assess potential vaccines in clinical trials. In fact, both of the subunit vaccines mentioned above were designed based on what was known about their respective antigens, particularly the antigen's role in the pathogenesis of infection (Cassone et al. 2007; Phan et al. 2007). When formulating recombinant fungal vaccines, special consideration must also be given to the method chosen for its synthesis, as native glycosylation is lost in bacterial expression systems. Lack of native glycosylation decreases the immunogenicity of some fungal proteins (Lam et al. 2005; Levitz and Specht 2006; Specht et al. 2007).

\section{Conjugate Vaccines}

Although epitopes on polysaccharides can be recognized by $\mathrm{B}$ - and $\mathrm{T}$-cell receptors, for antigens to be presented to $\mathrm{T}$ cells, they must be loaded on MHC molecules, which only bind peptides. To bypass this bias toward peptide antigens, vaccinologists have conjugated polysaccharides to proteins thus creating antigens that can be presented on MHC molecules and select $\mathrm{B}$ and $\mathrm{T}$ cells that that are specific for glycan epitopes. The first conjugate vaccine developed for fungal infections contained C. neoformans capsular polysaccharide, glucuronoxylomannan (GXM) covalently linked to tetanus toxoid (TT). Given with monophosphoryl lipid A (MPL) as an adjuvant, this antigen elicited high levels of IgG and IgA specific for GXM and protected $70 \%$ of intravenously challenged mice. Protection from mortality was at least partially conferred by elicited antibodies, as adoptive transfer of antisera from immunized animals also protected mice from a lethal inoculum of intravenously administered C. neoformans (Devi 1996).

Torosantucci et al. (2005) have conjugated laminarin, a $\beta$-glucan polysaccharide derived from brown algae, to inactivated diphtheria toxin (CRM) to create a universal fungal vaccine. This conjugate, injected with complete Freund's 
adjuvant (CFA) subcutaneously, protected $70 \%$ and $\sim 80 \%$ of $\mathrm{CD} 2 \mathrm{~F} 1$ mice from invasive candidiasis and aspergillosis, respectively, whereas $\sim 20 \%-30 \%$ of mice given CFA or CRM alone survived either infection. The laminarin-CRM conjugate was also effective in treating vaginal candidiasis in Wistar rats when given with cholera toxin as an adjuvant (Torosantucci et al. 2005).

A $\beta$-1,2-mannotriose conjugated to a peptide segment from fructose bisphosphate aldolase (Fba) and TT has also been tested as a possible anti-Candida vaccine. Fba protein and $\beta-1,2$-mannose are antigens found on the surface of Candida spp. Different formulations of this vaccine were tried in a BALB/c invasive candidiasis model. One group received the conjugate $(\beta$-man-Fba-TT) by itself, another received conjugate and alum, and the third group received conjugate along with MPL. The conjugate only and conjugate plus alum groups received the most protection as $100 \%$ of the mice survived infection, compared with $0 \%-20 \%$ in the control group, whereas $\sim 60 \%$ mice receiving the conjugate and MPL formulation survived the infection. In this strategy, coupling of the inactivated tetanus toxin to the glycanpeptide conjugate was crucial for the success of the vaccine, as $100 \%$ of the mice immunized with just $\beta$-1,2-mannotriose-Fba succumbed to infection (Xin et al. 2012).

Conjugating proteins to polysaccharides enables the immune system to recognize abundant fungal cell wall glycan components, increasing the chance that antibodies will recognize the pathogen. Additionally, this strategy can be used to target saccharide epitopes that are common to all fungi, particularly $\beta$-glucans, thereby creating one vaccine that is effective against a broad range of pathogenic fungi. This may be particularly advantageous to patients who are iatrogenically immunosuppressed and at high risk for developing disseminated infections from multiple fungal pathogens. Although highly needed, developing immunizations for this population can be quite challenging, as they are less likely to respond to acellular vaccines and may be at risk for developing disease after attenuated immunizations. However, acel- lular vaccines may retain efficacy if given before the start of the immunosuppressive regimen (Bozza et al. 2009).

\section{CONCLUSION}

Largely because of medical advances and the emergence of AIDS, the number of immunosuppressed individuals susceptible to fungal infections has exponentially increased in the last 50 years. High mortality rates associated with IFIs have emergently precipitated the need for new therapeutics. In addition, advancements in understanding host-pathogen interactions in mucosal infections and IFIs have brought several immunotherapy and vaccine strategies to the preclinical stage of development. Out of the strategies that have been shown to be successful at this stage, a few have gone on to be tested in clinical trials. Lack of awareness about the severity of the human and economic toll fungal infections inflict worldwide has contributed to a poor funding climate for medical mycology (Brown et al. 2012). Despite these challenges, some strategies described above have reached clinical trials and show some promise as they advance in clinical development. Hence, there is hope that with the further development of immunotherapies and vaccines, at least some lethal fungal infections will become rare once again.

\section{REFERENCES}

ACIP. 2011. General recommendations on immunizationRecommendations of the Advisory Committee on Immunization Practices (ACIP). MMWR Recomm Rep 60: $1-64$.

Armstrong-James D, Harrison TS. 2012. Immunotherapy for fungal infections. Curr Opin Microbiol 15: 434439.

Beenhouwer DO, Yoo EM, Lai CW, Rocha MA, Morrison SL. 2007. Human immunoglobulin G2 (IgG2) and IgG4 but not IgG1 or IgG3, protect mice against Cryptococcus neoformans infection. Infect Immun 75: 1424-1435.

Bozza S, Clavaud C, Giovannini G, Fontaine T, Beauvais A, Sarfati J, D’Angelo C, Perruccio K, Bonifazi P, Zagarella S, et al. 2009. Immune sensing of Aspergillus fumigatus proteins, glycolipids, and polysaccharides and the impact on Th immunity and vaccination. J Immunol 183: 2407 2414. 
Brown GD, Denning DW, Gow NA, Levitz SM, Netea MG, White TC. 2012. Hidden killers: Human fungal infections. Sci Transl Med 4: 165rv113.

Bruhns P. 2012. Properties of mouse and human IgG receptors and their contribution to disease models. Blood 119: 5640-5649.

Bryan RA, Jiang A, Howell RC, Morgenstern A, Bruchertseifer F, Casadevall A, Dadachova E. 2010. Radioimmunotherapy is more effective than antifungal treatment in experimental cryptococcal infection. J Infect Dis 202: 633-637.

Capilla J, Clemons KV, Liu M, Levine HB, Stevens DA. 2009. Saccharomyces cerevisiae as a vaccine against coccidioidomycosis. Vaccine 27: 3662-3668.

Capodicasa C, Chiani P, Bromuro C, De Bernardis F, Catellani M, Palma AS, Liu Y, Feizi T, Cassone A, Benvenuto $\mathrm{E}$, et al. 2011. Plant production of anti- $\beta$-glucan antibodies for immunotherapy of fungal infections in humans. Plant Biotechnol J 9: 776-787.

Carvalho A, Cunha C, Bozza S, Moretti S, Massi-Benedetti C, Bistoni F, Aversa F, Romani L. 2012. Immunity and tolerance to fungi in hematopoietic transplantation: Principles and perspectives. Front Immunol 3: 156.

Cassone A. 2008. Fungal vaccines: Real progress from real challenges. Lancet Infect Dis 8: 114-124.

Cassone A, De Bernardis F, Santoni G. 2007. Anticandidal immunity and vaginitis: Novel opportunities for immune intervention. Infect Immun 75: 4675-4686.

Chu JH, Feudtner C, Heydon K, Walsh TJ, Zaoutis TE. 2006. Hospitalizations for endemic mycoses: A populationbased national study. Clin Infect Dis 42: 822-825.

Cutler JE, Deepe GS Jr, Klein BS. 2007. Advances in combating fungal diseases: Vaccines on the threshold. Nat Rev Microbiol 5: 13-28.

Dadachova E, Nakouzi A, Bryan RA, Casadevall A. 2003. Ionizing radiation delivered by specific antibody is therapeutic against a fungal infection. Proc Natl Acad Sci 100: 10942-10947.

Dan JM, Levitz SM. 2006. Prospects for development of vaccines against fungal diseases. Drug Resist Updat 9: $105-110$.

De Bernardis F, Amacker M, Arancia S, Sandini S, Gremion C, Zurbriggen R, Moser C, Cassone A. 2012. Avirosomal vaccine against candidal vaginitis: Immunogenicity, efficacy and safety profile in animal models. Vaccine 30: $4490-4498$.

Devi SJ. 1996. Preclinical efficacy of a glucuronoxylomannan-tetanus toxoid conjugate vaccine of Cryptococcus neoformans in a murine model. Vaccine 14: 841-844.

Dimopoulos G, Antonopoulou A, Armaganidis A, Vincent JL. 2013. How to select an antifungal agent in critically ill patients. J Crit Care 28: 717-727.

Dwivedi P, Thompson A, Xie Z, Kashleva H, Ganguly S, Mitchell AP, Dongari-Bagtzoglou A. 2011. Role of Bcrl-activated genes Hwpl and Hyrl in Candida albicans oral mucosal biofilms and neutrophil evasion. PLoS ONE 6: e16218.

Guimaraes AJ, Frases S, Gomez FJ, Zancope-Oliveira RM, Nosanchuk JD. 2009. Monoclonal antibodies to heat shock protein 60 alter the pathogenesis of Histoplasma capsulatum. Infect Immun 77: 1357-1367.
Hamad M. 2008. Antifungal immunotherapy and immunomodulation: A double-hitter approach to deal with invasive fungal infections. Scand J Immunol 67: 533-543.

Hardison SE, Brown GD. 2012. C-type lectin receptors orchestrate antifungal immunity. Nat Immunol 13: 817822.

Hogan LH, Klein BS, Levitz SM. 1996. Virulence factors of medically important fungi. Clin Microbiol Rev 9: 469488.

Hole CR, Wormley FL Jr. 2012. Vaccine and immunotherapeutic approaches for the prevention of cryptococcosis: Lessons learned from animal models. Front Microbiol 3: 291.

Huang H, Ostroff GR, Lee CK, Agarwal S, Ram S, Rice PA, Specht CA, Levitz SM. 2012. Relative contributions of dectin- 1 and complement to immune responses to particulate $\beta$-glucans. J Immunol 189: 312-317.

Huang H, Ostroff GR, Lee CK, Specht CA, Levitz SM. 2013. Characterization and optimization of the glucan particlebased vaccine platform. Clin Vaccine Immunol 20: 15851591.

Iannitti RG, Carvalho A, Romani L. 2012. From memory to antifungal vaccine design. Trends Immunol 33: 467-474.

Ibrahim AS, Luo G, Gebremariam T, Lee H, Schmidt CS, Hennessey JP Jr, French SW, Yeaman MR, Filler SG, Edwards JE Jr. 2013. NDV-3 protects mice from vulvovaginal candidiasis through T- and B-cell immune response. Vaccine 31: 5549-5556.

Kehry MR, Castle BE. 1994. Regulation of CD40 ligand expression and use of recombinant CD40 ligand for studying B cell growth and differentiation. Semin Immunol 6: 287-294.

Kehry MR, Hodgkin PD. 1993. Helper T cells: Delivery of cell contact and lymphokine-dependent signals to B cells. Semin Immunol 5: 393-400.

Lam JS, Mansour MK, Specht CA, Levitz SM. 2005. A model vaccine exploiting fungal mannosylation to increase antigen immunogenicity. J Immunol 175: 7496-7503.

Latge JP. 2010. Tasting the fungal cell wall. Cell Microbiol 12: $863-872$.

Levine MM, Sztein MB. 2004. Vaccine development strategies for improving immunization: The role of modern immunology. Nat Immunol 5: 460-464.

Levitz SM, Golenbock DT. 2012. Beyond empiricism: Informing vaccine development through innate immunity research. Cell 148: 1284-1292.

Levitz SM, Specht CA. 2006. The molecular basis for the immunogenicity of Cryptococcus neoformans mannoproteins. FEMS Yeast Res 6: 513-524.

Liu M, Capilla J, Johansen ME, Alvarado D, Martinez M, Chen V, Clemons KV, Stevens DA. 2011a. Saccharomyces as a vaccine against systemic aspergillosis: "The friend of man" a friend again? J Med Microbiol 60: 1423-1432.

Liu M, Clemons KV, Bigos M, Medovarska I, Brummer E, Stevens DA. 2011b. Immune responses induced by heat killed Saccharomyces cerevisiae: A vaccine against fungal infection. Vaccine 29: 1745-1753.

Liu M, Clemons KV, Johansen ME, Martinez M, Chen V, Stevens DA. 2012a. Saccharomyces as a vaccine against systemic candidiasis. Immunol Invest 41: 847-855. 
E. Santos and S.M. Levitz

Liu M, Machova E, Nescakova Z, Medovarska I, Clemons KV, Martinez M, Chen V, Bystricky S, Stevens DA. 2012b. Vaccination with mannan protects mice against systemic aspergillosis. Med Mycol 50: 818-828.

Lopes LC, Guimaraes AJ, de Cerqueira MD, Gomez BL, Nosanchuk JD. 2010. A Histoplasma capsulatum-specific IgG1 isotype monoclonal antibody, $\mathrm{H} 1 \mathrm{C}$, to a 70-kilodalton cell surface protein is not protective in murine histoplasmosis. Clin Vaccine Immunol 17: 1155-1158.

Magalhaes A, Ferreira KS, Almeida SR, Nosanchuk JD, Travassos LR, Taborda CP. 2012. Prophylactic and therapeutic vaccination using dendritic cells primed with peptide 10 derived from the 43-kilodalton glycoprotein of Paracoccidioides brasiliensis. Clin Vaccine Immunol 19: 23-29.

Mestas J, Hughes CC. 2004. Of mice and not men: Differences between mouse and human immunology. J Immunol 172: 2731-2738.

Mukherjee J, Nussbaum G, Scharff MD, Casadevall A. 1995. Protective and nonprotective monoclonal antibodies to Cryptococcus neoformans originating from one B cell. J Exp Med 181: 405-409.

Murphy K, Travers P, Walport M, Janeway C. 2012a. Janeway's immunobiology, p. 354. Garland, New York.

Murphy K, Travers P, Walport M, Janeway C. 2012b. Janeway's immunobiology, p. 402. Garland, New York.

NIH. 2010. A phase I clinical trial for recurrent vulvovaginal candidiasis. Identification No. NCT01067131, National Institutes of Health, Bethesda, MD, clinicaltrials.gov.

Nussbaum G, Cleare W, Casadevall A, Scharff MD, Valadon P. 1997. Epitope location in the Cryptococcus neoformans capsule is a determinant of antibody efficacy. J Exp Med 185: 685-694.

Pappagianis D. 1993. Evaluation of the protective efficacy of the killed Coccidioides immitis spherule vaccine in humans. The Valley Fever Vaccine Study Group. Am Rev Respir Dis 148: 656-660.

Park BJ, Wannemuehler KA, Marston BJ, Govender N, Pappas PG, Chiller TM. 2009. Estimation of the current global burden of cryptococcal meningitis among persons living with HIV/AIDS. AIDS 23: 525-530.

Perlroth J, Choi B, Spellberg B. 2007. Nosocomial fungal infections: Epidemiology, diagnosis, and treatment. Med Mycol 45: 321-346.

Pfaller MA, Diekema DJ. 2010. Epidemiology of invasive mycoses in North America. Crit Rev Microbiol 36: 1-53.

Phan QT, Myers CL, Fu Y, Sheppard CD, Yeaman MR, Welch WH, Ibrahim AS, Edwards JE Jr, Filler SG. 2007. Als3 is a Candida albicans invasin that binds to cadherins and induces endocytosis by host cells. PLoS Biol 5: e64.

Pirofski LA, Casadevall A. 1998. Use of licensed vaccines for active immunization of the immunocompromised host. Clin Microbiol Rev 11: 1-26.

Ricklin D, Hajishengallis G, Yang K, Lambris JD. 2010 Complement: A key system for immune surveillance and homeostasis. Nat Immunol 11: 785-797.

Romani L, Bistoni F, Perruccio K, Montagnoli C, Gaziano R, Bozza S, Bonifazi P, Bistoni G, Rasi G, Velardi A, et al. 2006. Thymosin $\alpha 1$ activates dendritic cell tryptophan catabolism and establishes a regulatory environment for balance of inflammation and tolerance. Blood 108: 22652274.
Roush SW, Murphy TV. 2007. Historical comparisons of morbidity and mortality for vaccine-preventable diseases in the United States. JAMA 298: 2155-2163.

Schmidt CS, White CJ, Ibrahim AS, Filler SG, Fu Y, Yeaman MR, Edwards JE Jr, Hennessey JP Jr. 2012. NDV-3, a recombinant alum-adjuvanted vaccine for Candida and Staphylococcus aureus, is safe and immunogenic in healthy adults. Vaccine 30: 7594-7600.

Schroeder HW Jr, Cavacini L. 2010. Structure and function of immunoglobulins. J Allergy Clin Immunol 125: S41S52.

Specht CA, Nong S, Dan JM, Lee CK, Levitz SM. 2007. Contribution of glycosylation to T cell responses stimulated by recombinant Cryptococcus neoformans mannoprotein. J Infect Dis 196: 796-800.

Spellberg BJ, Ibrahim AS, Avanesian V, Fu F, Myers C, Phan QT, Filler SG, Yeaman MR, Edwards JE Jr. 2006. Efficacy of the anti-Candida rAls $3 \mathrm{p}-\mathrm{N}$ or rAls $1 \mathrm{p}-\mathrm{N}$ vaccines against disseminated and mucosal candidiasis. J Infect Dis 194: 256-260.

Spellberg B, Ibrahim AS, Yeaman MR, Lin L, Fu Y, Avanesian V, Bayer AS, Filler SG, Lipke P, Otoo H, et al. 2008. The antifungal vaccine derived from the recombinant $\mathrm{N}$ terminus of Als $3 p$ protects mice against the bacterium Staphylococcus aureus. Infect Immun 76: 45744580.

Steinman RM, Banchereau J. 2007. Taking dendritic cells into medicine. Nature 449: 419-426.

Taborda CP, Juliano MA, Puccia R, Franco M, Travassos LR. 1998. Mapping of the T-cell epitope in the major 43kilodalton glycoprotein of Paracoccidioides brasiliensis which induces a Th-1 response protective against fungal infection in BALB/c mice. Infect Immun 66: 786-793.

Toews GB. 2001. Cytokines and the lung. Eur Respir J Suppl 34: $3 s-17 s$.

Torosantucci A, Bromuro C, Chiani P, De Bernardis F, Berti F, Galli C, Norelli F, Bellucci C, Polonelli L, Costantino P, et al. 2005. A novel glyco-conjugate vaccine against fungal pathogens. J Exp Med 202: 597-606.

Torosantucci A, Chiani P, Bromuro C, De Bernardis F, Palma AS, Liu Y, Mignogna G, Maras B, Colone M, Stringaro A, et al. 2009. Protection by anti- $\beta$-glucan antibodies is associated with restricted $\beta-1,3$ glucan binding specificity and inhibition of fungal growth and adherence. PLoS ONE 4: e5392.

Tritto E, Mosca F, De Gregorio E. 2009. Mechanism of action of licensed vaccine adjuvants. Vaccine 27: 3331-3334.

Vecchiarelli A, Pericolini E, Gabrielli E, Pietrella D. 2012. New approaches in the development of a vaccine for mucosal candidiasis: Progress and challenges. Front Microbiol 3: 294

Wormley FL Jr, Perfect JR, Steele C, Cox GM. 2007. Protection against cryptococcosis by using a murine $\gamma$ interferon-producing Cryptococcus neoformans strain. Infect Immun 75: 1453-1462.

Wozniak KL, Young ML, Wormley FL Jr. 2011. Protective immunity against experimental pulmonary cryptococcosis in T-cell-depleted mice. Clin Vaccine Immunol 18: $717-723$.

Wuthrich M, Filutowicz HI, Warner T, Deepe GS Jr, Klein BS. 2003. Vaccine immunity to pathogenic fungi over- 
comes the requirement for CD4 help in exogenous antigen presentation to $\mathrm{CD}^{+} \mathrm{T}$ cells: Implications for vaccine development in immune-deficient hosts. J Exp Med 197: 1405-1416.

Xin H, Cartmell J, Bailey JJ, Dziadek S, Bundle DR, Cutler JE. 2012. Self-adjuvanting glycopeptide conjugate vaccine against disseminated candidiasis. PLOS ONE 7: e35106.
Xue J, Chen X, Selby D, Hung CY, Yu JJ, Cole GT. 2009. A genetically engineered live attenuated vaccine of Coccidioides posadasii protects $\mathrm{BALB} / \mathrm{c}$ mice against coccidioidomycosis. Infect Immun 77: 3196-3208.

Yuan R, Casadevall A, Spira G, Scharff MD. 1995. Isotype switching from IgG3 to IgG1 converts a nonprotective murine antibody to Cryptococcus neoformans into a protective antibody. J Immunol 154: 1810-1816. 


\section{$\&_{\mathrm{CSH}}^{\infty} \&$ Cold Spring Harbor

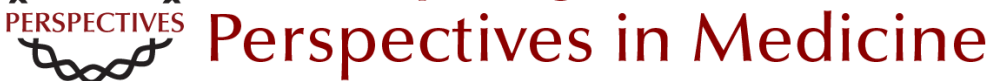

\section{Fungal Vaccines and Immunotherapeutics}

Evelyn Santos and Stuart M. Levitz

Cold Spring Harb Perspect Med 2014; doi: 10.1101/cshperspect.a019711

Subject Collection Human Fungal Pathogens

\section{Evolutionary Perspectives on Human Fungal Pathogens \\ John W. Taylor}
Black Molds and Melanized Yeasts Pathogenic to Humans Anuradha Chowdhary, John Perfect and G. Sybren de Hoog

Fungal Pathogens: Survival and Replication within Macrophages Andrew S. Gilbert, Robert T. Wheeler and Robin C. May

Innate Defense against Fungal Pathogens Rebecca A. Drummond, Sarah L. Gaffen, Amy G. Hise, et al.

Antifungal Pharmacokinetics and

Pharmacodynamics

Alexander J. Lepak and David R. Andes

Human Fungal Pathogens of Mucorales and

Entomophthorales

Leonel Mendoza, Raquel Vilela, Kerstin Voelz, et al.

Functional Profiling of Human Fungal Pathogen

Genomes

Alexi I. Goranov and Hiten D. Madhani

Aspergillus fumigatus and Related Species Janyce A. Sugui, Kyung J. Kwon-Chung, Praveen $R$. Juvvadi, et al.
Thermally Dimorphic Human Fungal Pathogens-Polyphyletic Pathogens with a Convergent

Pathogenicity Trait

Anita Sil and Alex Andrianopoulos

Mechanisms of Antifungal Drug Resistance Leah E. Cowen, Dominique Sanglard, Susan J. Howard, et al.

\section{Treatment Principles for Candida and Cryptococcus Laura C. Whitney and Tihana Bicanic}

The Human Mycobiome Patrick C. Seed

Treatment Principles for the Management of Mold Infections

Dimitrios P. Kontoyiannis and Russell E. Lewis

Adaptive Immunity to Fungi Akash Verma, Marcel Wüthrich, George Deepe, et al.

The Candida Pathogenic Species Complex Siobhán A. Turner and Geraldine Butler

\section{Fungal Morphogenesis} Xiaorong Lin, J. Andrew Alspaugh, Haoping Liu, et al.

For additional articles in this collection, see http://perspectivesinmedicine.cshlp.org/cgi/collection/ 